\title{
Mechanism of Salt Absorption by Plant Cells
}

\section{By Dr. W. J. V. Osterhout, Rockefeller Institute for Medical Research, New York}

$\mathrm{T}^{\mathrm{o}}$ solve the problem of the mechanism of the absorption of electrolytes by the plant cell, we need accurate knowledge of what goes on inside the cell. This cannot be obtained with cells of ordinary size. We have therefore studied very large multinucleate plant cells, especially those of Valonia ${ }^{1}$. Since this work has called forth comments ${ }^{2}$, due to misunderstanding, a brief statement of facts is submitted, although this statement is naturally far from being complete.

(1) Injury. A great advantage of Valonia is the ease with which injury can be detected. In our laboratory especial care has always been used to avoid working on injured cells. Dr. Steward concludes that our experiments with ammonium chloride were made with injured cells. Working at the high temperatures of Tortugas in the summer, he found that Valonia was easily injured by ammonium ehloride.

This may happen also in Bermuda in summer, but in winter cells are obtainable which benefit by concentrations of ammonium chloride up to $0.005 M$. They behave as plants usually do when given an optimum amount of nitrogen. In such experiments certain precautions are necessary, as we have gradually learned during several years of work. The proper handling of these cells requires considerable experience. When the internal concentration of $\mathrm{NH}_{4}+$ approaches $0 \cdot 3 M$ injury may result. This was not the case here.

The following evidences of injury are cited by Dr. Steward :

(a) Sodium entered more rapidly than in the controls. This is not significant in view of the fact that in other experiments the rate of entrance in the controls was very variable and was sometimes greater than in this case.

(b) Potassium went out 'with the gradient'. It may be misleading to speak of the passage of a cation 'with' or 'against' a gradient without considering the accompanying anion and the product of the ions, which is proportional to the chemical potential. 'To call this injury is to misunderstand the situation. For injury always causes an escape of potassium chloride which, though much more concentrated inside the cell than outside, is normally retained because the protoplasm is only slightly permeable to it. Injury quickly increases the permeability, and in consequence potassium chloride comes out and growth ceases.

Our experiments present a picture in no way resembling this. No chloride escaped. On the contrary, it continued to enter as usual 'against a gradient', a conclusive proof that the cell was not injured. (During this period the gain in moles of chloride was $14 \cdot 1$ per cent; the loss of potassium was about $15 \cdot 8$ per cent. Presumably potassium went out as potassium hydroxide, to which the protoplasm is normally very permeable.) At the same time ammonium entered ('against a gradient') and became more than a hundred times as concentrated inside as outside. This could not happen if the cell were injured.
Moreover, the cells were better than the controls in growth, in photosynthesis (unpublished work) and in general appearance. They lived indefinitely. In experiments lasting a month a few cells died, but the death rate was no higher than in the controls. The expression "corrected volume" applied to these cells has nothing to do with the death of cells. (All volumes were multiplied by the same factor.)

(c) A misunderstanding must be responsible for the following statement. "Considerable prominence has been given to the fact that an external $p \mathrm{H}$ of $5 \cdot 5$ which causes irreversible injury and death also produces loss of potassium ions." In our work the lowest external $p H$ was $6 \cdot 8$, at which there was no sign of injury. According to Steward, 7 is optimal for absorption.

(2) Metabolism. Dr. Steward concludes that the study of Valonia must be misleading because its metabolism is less than that of storage tissues (for example, potato) the chemical activity of which has been abnormally raised by being cut into thin slices and placed in well-aerated solutions. (Cutting increases abnormally the output of carbon dioxide.)

This involves the relation of metabolism to the absorption of electrolytes. In Valonia, the production of carbon dioxide (and of other organic acids) keeps the chemical potential of potassium hydroxide less inside than outside : hence potassium hydroxide continues to enter. The metabolism of Valonia is ample for this purpose. The $p H$ of the sap is about $5 \cdot 8$ as compared with $8 \cdot 0$ to $8 \cdot 2$ of the sea-water. In a cell $1 \mathrm{~cm}$. in diameter the volume of the protoplasm is less than one per cent of the total. Hence a correct estimate of metabolism, based on the amount of protoplasm, will be more than a hundred times as great as one based on the volume of the cell. In the laboratory the growth in volume under favourable conditions is $0 \cdot 5-2$ per cent per day.

Other aspects of metabolism may be important : if so, it should eventually be possible to demonstrate their roles as clearly as that of carbon dioxide in Valonia (and in models).

(3) Theoretical. (a) When we increase the external $p H$, potassium goes in more rapidly. Its entrance decreases the activity of water inside and raises the osmotic pressure, so that water enters more rapidly : in consequence, the internal concentration of potassium remains approximately constant. Hence the only way to find out how fast potassium enters is to measure the increase of moles of potassium in the cell.

(b) If potassium enters chiefly as potassium hydroxide, its rate of entrance will increase with increasing $p \mathrm{H}$ until secondary changes begin to interfere. Such secondary changes become striking at high $p \mathrm{H}$ values and undoubtedly begin much lower. It is therefore impossible on theoretical grounds to predict the optimum $p H$. If it should turn out to be 7 in any given case, it would not invalidate the hypothesis.

(c) Since Valonia is able to accumulate electrolytes without the complications of storage tissues -for example, the presence of intercellular spaces and of injured or altered cells in the sliced tissues, the fact that the cells are placed under abnormal 
conditions, and the impossibility of obtaining the cell sap without contamination and chemical change-we must perforce congratulate ourselves on finding such a satisfactory organism for study.

Certain principles which appear to govern accumulation in Valonia are so simple that they have been embodied in models in which potassium chloride enters until its chemical potential inside becomes several times as great as outside. (This depends on the bubbling of carbon dioxide through the artificial sap to imitate its production by the living cell.) Such increase in chemical potential involves an expenditure of energy, which comes from chemical reactions (as it does in the cell).

Some of these principles play an important role in other organisms. Future research must reveal the extent of their application.

1 Osterhout, W. J. V., Ergebnisse der Physiol., 35, 967 ; 1935.

2 Steward, F, C., NATore, 135, 553; 1935.

\section{By Dr. F. C. Steward, Birkbeck College, University of London}

ONLY minor comments are necessary to the reply of Dr. Osterhout, which is devoted mainly to the question of injury to $V$. macrophysa by ammonium chloride.

Even if the ammonia experiments are free from the suspicion of injury, the fact still remains that the subsequent movements of potassium and sodium neither necessitate a distinction between ions and molecules nor are they in the direction usually associated with accumulation.

In order to evade the unfortunate implications of the results with respect to sodium, Dr. Osterhout implies that a difference between the 'control' and 'ammonia' groups which, on the data given, is clearly significant, is after all not real. This difference, whether due to injury or not, is certainly in a direction not in accord with the theory and cannot be dismissed, because of the behaviour of cells (unpublished) which were not strict controls for this experiment ${ }^{1}$.

Since injury "in the summer time", even at Bermuda, to $V$. macrophysa by ammonium chloride is now acknowledged, readers will serutinise even more carefully any crucial experiments which involve this salt, and, no doubt, demand more precise designation than the vague terms 'summer' and 'winter', of the seasonal variations which can be tolerated and the limits of internal concentration which differentiate an 'injurious' from a 'beneficial' effect (it is stated ${ }^{2}$ that injury occurs in the Bermuda material at a concentration "less than $0.3 \mathrm{M}$ ".)

However, the major problem is not the applicability of the theory to the absorption of ammonia, or even its ability to explain the secondary effects which this substance produces on the distribution of potassium and sodium, but rather its generalisation to embrace the initial accumulation of all electrolytes, even the alkali halides.

To the discussion of the effects of external reaction, in so far as they test the theory, Dr. Osterhout contributes two observations although he does not answer the more searching criticisms. One denies that the theory derived any of its support from its undoubted ability to explain qualitatively the behaviour of cells in a medium equally acid as the sap, and the second insists that vague, unspecified "secondary" effects obscure the direct effects of external hydroxyl ion concentration which the theory demands. A theory which, alroady heavily weighted with hypothesis, fails to satisfy a direct test and can only be retained by resort to such vague assumptions would be better abandoned.

Clearly, one cannot conclude from the work on Valonia that the simple mechanism suggested will explain adequately the general facts of salt accumulation by cells ${ }^{3}$. Dr. Osterhout may dismiss the metabolic processes which accompany rapid salt accumulation in storage tissue by regarding them as abnormal chemical activity; but if so, he must a]so be prepared to eliminate as "abnormal" some of the most fundamental attributes of actively growing cells which, in roots and developing leaves (aquatic and otherwise), are now known to be as intimately concerned with salt accumulation as in the cut storage tissues. The theory of "thermodynamic potentials of free base" and its subsidiary hypotheses is completely inadequate as an explanation of the behaviour of any or all of these systems.

If this discussion emphasises that the problem is still an open one, it may not have been in vain.

${ }^{1}$ A. G. Jacques and W. J. V. Osterhout, J. Gen. Phys., 14, 309 ; 1930. ${ }^{2}$ W. C. Cooper and W. J. V. Osterhout, J. Gen. Phys., 14, 124; 1930.

${ }^{3}$ F. C. Steward, Ann. Rev. Biochem., 4, 527; 1935.

\section{Progress of Building Research*}

$\mathrm{T}$ $\mathrm{HE}$ work of the Building Research Board embraces the products of such a wide range of industries and touches so closely upon the lives of the people that any description of its work is not only of scientific value but is also of importance to the industries directly and indirectly concerned, while at the same time the record is a serious contribution to the material side of social improvement. In this last connexion, it is interesting to note in the annual report for 1934 , recently issued, that the Board's resources for research and inquiry have been

*Department of Scientific and Industrial Research. Report of the Building Research Board, with the Report of the Director of Building Research, for the Year 1934. Pp. $x+174+14$ plates. (London : H.M. Stationery Office, 1935.) 38 . 6d. net. placed at the disposal of a departmental committee appointed by the Ministry of Health to report on materials and methods of construction suitable for working-class flats.

In the search for fire-proof materials, officers of the Building Research Station have worked in close co-operation with the Fire Offices Committee in the design of the laboratory for fire resistance tests at Elstree (NATURE, Dec. 21, p. 996). The need for data on the transmission of sound through the fabric of a building has led to the provision at the Research Station, in conjunction with the National Physical Laboratory, of facilities for full-scale tests on floors and to the setting up of a special Sub-Committee on Sound Transmission. The problem of impact noises 